\title{
Research on Cross-Cultural Management Related Issues in Foreign Companies
}

\author{
Ke Yan ${ }^{1, a}$ \\ ${ }^{1}$ Nanyang Medical College, Nanyang, Henan, China, 473000 \\ ${ }^{\mathrm{a}}$ email,
}

Keywords: Foreign Companies, Cultural Conflict, Cross-Cultural Management, Company Culture

\begin{abstract}
In the first half of 2010, in a number of large-scale foreign-funded enterprises, jumping events and employee strikes and collective occur frequently, cultural conflicts reached incandescent degree. How ablation conflict of different cultures, through effective and powerful cross-cultural management to achieve the participation and integration of cross-cultural, promote foreign companies in China to have healthy, long-term development, it has become an important issue faced by all foreign companies in China.
\end{abstract}

\section{Introduction}

January 2010 to May, just a few months time, the kingdom called the world's foundry Taiwan-funded enterprises in Shenzhen Foxconn has occurred continuously since 12 employees committed suicide. Alas it called on the people to ask: do these tragedies can be avoided? From the management point of view, managers group to other classes or cultural groups' indifference and arrogance is a major cause of the party and constantly self-denial. Inner-funded enterprises, this indifference and arrogance will cause tension and conflict between different sectors, and foreign-funded enterprises, the added factor of cultural conflict, which makes foreign-funded enterprises in the contradictions and conflicts more complex. By some foreign visits, I found, face cultural conflicts, the correct implementation of cross-cultural management strategies companies can always cope with this complicated situation. Based on this, this article will focus on the impact of cultural conflict on the corporate culture and the implementation of cross Cultural management strategies.

\section{The Cultural Conflict: A Complex Concept}

It is generally believed that cultural conflict occurs mainly in the spiritual culture, institutional culture, behavior and other aspects. Conflict of spiritual and cultural mainly includes values, including conflict, ways of thinking and so on. Due to the different cultural origins of each country, different historical backgrounds, different development process, leading to differences in national cultural values. Darlington references a dram Alpena research on cross-cultural with a country that people will use the same method to solve the problem, because cohesive culture is a prerequisite for social stability. Is generally believed that Japanese companies emphasize people-oriented, and for you, focus on teamwork, focus on innovation, American companies focus on freedom and individuality, the pursuit of diversity, adventurous, high German corporate integrity, attention to rules, strict management, careful, and China companies are more focused on human, stress collectivism, process-oriented, high risk aversion. Corporate culture steeped in different individuals suddenly exposed to very likely occur in other cultures so-called "culture shock" to disregard such a conflict can only be increased to suspend or death different cultural cooperation process. System Culture is part of the corporate culture, businesses can use the system in a certain economic and cultural environment and the production and management practices to manage the formation of consensus. Differences in institutional culture is mainly manifested in two aspects: First, in the management contract to the rule of law or rule of man; Second, enterprises face when entering the international market, foreign culture is keep Ling native culture even more exotic culture and above or exotic cultural fusion, concluding mutually beneficial. Western culture emphasizes the awareness 
of rational thinking habits and fair, and in the enterprise management is to establish and improve the enterprise system. The Chinese pay attention to the spirit of the rule of man, pay attention to the role of people, the role of morality, Chinese enterprises have established a system, but the system is dead, people are living, you experience difficulty, employees first thought is how to through relationships or acquaintances solve problems, so that people are keen to establish personal relationships. Some foreign-funded enterprises to enter China to take keep national or regional cultural attitudes, copy the parent culture, finally resulting in strong dissatisfaction of employees, take drastic action.

Enterprise rigid conservative attitude that roughly three reasons: First, do not understand the other culture, mistakenly believe that the other side did not differ with their, or the other should be able to accept their own culture; the second is to ignore individual differences, to focus only on the overall impression of each other's culture, depth and thus can not objectively observe another culture, lose their sensitivity. Third, ethnocentrism, that is in accordance with this standard and the concept of national culture to understand and measure all other ethnic cultures. I keep this cultural moment is not conducive to the development of foreign-funded enterprises in China, even when serious devastated the entire enterprise. The correct approach is flexible to adjust their management style for the local Chinese cultural characteristics, find the fusion point of two cultures as soon as possible, to create a culture of a third party acceptable to both sides. Behavior culture is a culture of the outermost layer of the most direct way and in particular the natural and social environment has long habits of behavior from the accumulation. It is divided into verbal behavior and nonverbal behavior. As people's attitude towards time; eating, talking to people, socialize or wearing habits, etc., reflect different national culture, incarnate the values and different ways of thinking. Different cultures develop different customs and behavior in one culture may be accepted practice intolerable and understanding another culture. China's foreign-funded enterprises in management, managers should pay attention to these details.

\section{The Cultural Conflict of Organization: One Phenomenon Needs to Digestion}

Some cultural conflict made a lengthy definition: a period of cultural conflict, a national dominant cultural model is no longer valid because the spiritual or cultural regulate social and individual behavior in a crisis, while the new culture characteristics and began experiencing old culture or cultural patterns of exclusion and spirit of resistance, so he started between the new cultural pattern or the cultural spirit of confrontation. We still can not agree with this point of view with regard to the definition of cultural conflict because the weakening of old cultural patterns arising, but it does give us a little inspiration: Which culture is more powerful Two Ideas collision of cultures inevitably lead to, those considered to be in culture will be a disadvantage to the weak stance dormant down in a sudden outbreak of what they considered a suitable point in time will usually invisible outer manifestation of conflict. For an organization, the explicit conflict is often fatal.

Since the beginning of 2010, it took place more than a dozen Foxconn employees suicides, followed by May 17 at the Honda transmission plant in Nanhai (Japanese); May 31 in Beijing Science and Technology Co., Ltd. Xingyu car (Korean capital); 6 February 7 in Kunshan Huaqiao Shuyuan Machinery factory (Taiwan); synthesis Ltd. (Japanese) staff frequently strike took place June 17 in Tianjin Toyota, at the end of June and early July and another in two well-known Japanese Shanghai and Wuxi enterprises Sharp Nikon broke employees collective strike. These extreme events more in appearance economic conflict of interest exists, but in the framework of the rule of law, economic

Conflicts of interest generally have relatively smooth path to solve, because the more the nature of improper corporate disregard for cultural conflict and cross-cultural management strategies. According to the survey data show that about $82 \%$ of multinational companies fail because of cross-cultural management failure caused. There are about one-third of famous multinational companies because pluralistic culture mismanagement faced internal tension situation. China there is a flood of foreign-funded enterprises, the quality of their level of development and the development of China's economic development plays an important role in these enterprises to maintain long-term in China, sustained healthy development, we must be fully aware of the correct 
handling of cultural conflict for an enterprise importance. A mature culture system always contains conflicts and digestion method. A mature business certainly has the courage to face the cultural conflict and courage, because in spite of cultural conflict is inevitable, but not always in a radical form. Most cultural clashes individual level, through a certain adjustment method can contribute to adapt to different cultures and change, thereby generating a new corporate culture. Therefore, the digestion of cultural conflict of organization does not to resist or eliminate these conflicts, but rather to promote the different classes, different cultural groups between understanding and factoring.

\section{Cross-Cultural Management: An Important Guarantee for the Healthy Development of Foreign-Funded Enterprises}

The so-called cross-cultural management, also known as cross-cultural management, cross-cultural management refers to the conditions to overcome the conflict of different cultures carried out. Its purpose is different forms of culture, the design of the practical organization and management mechanism, to maximize the use of corporate and explore the potential and value. Cross-cultural enterprise management process, both expressed as a discrete process or conflict between different cultures, but also the performance of the intersection or the integration of different cultures. The so-called "cultural conflict" refers to conflicting between different forms of culture or cultural factors, mutually exclusive processes; the so-called "cultural integration", it means bonded to each other or cultural factors change between the different forms of mutual absorption the process of. Cultural conflict and cultural integration as two cultural intersections are closely connected in the process of convergence of the two cultures which always coexist, accompanied by the line. Because the reality of heterogeneous team that cultural conflict is inevitable, and discrete, and with the real interests and objectives to the selection of cultural integration and make it possible. Through effective cross-cultural management, reduce operating foreign affairs cultural conflict and achieve China's foreign economic and cultural environment of dual adaptation in China, so that acculturation towards economic integration has become the healthy development of foreign companies in China basic policies and important guarantee. To resolve cross-cultural conflicts, there are three options available: Suppress, compromise and integration. Ling means a more play the role of the ruler of the organization a culture superior to other cultures, decision-making and behavior within the organization are subject to this cultural domination, while other cultures were suppressed. The advantage of this kind of approach in the short term to be able to form a "unity" of the organizational culture, but its drawback is not conducive to absorbing, but also because of other cultures have been suppressed and its members can easily produce a strong aversion eventually exacerbate conflict . Means a compromise between different cultures take compromise and concession approach deliberately ignored to avoid cultural differences, so as to achieve common ground in order to achieve harmony and stability within the organization, but this is often behind the harmony and stability of the latent crisis, only when each cultural differences between the very hour, be possible to achieve a compromise. Fusion refers to the recognition of different cultural, attention to the differences between them on the basis of mutual respect, mutual complement and mutual coordination, thus forming a kind you have me, I have you in the unity of the new organizational culture that unified culture not only has a strong stability and bicultural "hybrid" advantage. China's foreign-funded cross-cultural management should take cultural integration program, make sure you understand the Chinese culture, the Chinese and foreign two cultures together organically, construct a enterprise content containing both parent and can adapt to Chinese culture the new corporate culture environment.

\section{Leap Obstacles and Achieve Win-Win Situation: the Concrete Strategies of Cross-Cultural Management}

Cross-cultural management of foreign companies in China face many obstacles on the one hand, management is bound to be constrained China's environment, it is not only to comply with the relevant Chinese laws and regulations, institutions, and its organization and management system 
must be consistent with Chinese culture adaptation; on the other hand, foreign-funded enterprises have two-way cross-cultural management, its staff come from the Chinese mainland, the enterprise management from different countries and regions have a long-term process of adaptation, communication between Chinese and foreign could be manifold, , multi-level integration of different management style is long-term. China's foreign-funded enterprises there is a striking fusion of Chinese and foreign conflicts and two cultures, for managers, the key is how to cross the barriers of cultural differences, and seek the creation of a mutually recognized and accepted at the juncture of two cultures , to play the advantages of the two cultures of management.

Establish Correct Concept of Cross-Cultural Management. Recognize and understand the objective existence of cultural differences, attention to Chinese language and culture, economic and legal aspects of learning and understanding, while foreign executives to China to work, they tend to encounter many difficulties, its own culture, language, values, thinking and other factors in the form of cross-cultural management will be an obstacle, conflict, and the impact of cross-business strategy. Understanding cultural differences is a necessary condition for the development of cross-cultural management capability. Managers should learn to cultural differences as an advantage, not just a disadvantage. Proper and full use of cultural differences and creates opportunities for enterprise development, the correct treatment and dealing with cultural contradictions and conflicts, not only will not be an obstacle and it will become a source of dynamic and innovative enterprise development. Key cross-cultural management is people management, should be full implementation of cross-cultural management. Since cross-cultural management subjects and objects are related to the person, so foreign companies in China to emphasize the management of people, both Chinese management personnel to make a deep understanding of corporate culture of the foreign parent, but also so that operators have the ability to integrate cultural managerial staff as an important duty of cross-cultural management. Through the strengthening of all members of the company's cross-cultural management, so that the new culture in the management of real play.

Identify Cultural Differences, Seek Common and Establish Correct Cross-Cultural Management Strategies. The main underlying causes of cultural conflict are: ethnocentric, self-centered management and communication misunderstanding. Culture has no better or worse, the strength of the points. Based must abandon ethnocentric self-centered approach to management. Foreign companies in China must first fully understand the Chinese culture, and then to find common ground or balance FOREIGN two cultures. Due to cultural conflicts are caused by cultural differences, cultural differences must be analyzed to identify. Degree and type of cultural differences and cultural conflicts Cultural conflicts caused by different norms are different. Both by foreign companies in China's deep-rooted influence of foreign cultures in China from the parent company's management process, but also inevitably influenced by Chinese culture. When conducting cross-cultural management, should be based on national or regional culture and Chinese culture to fully understand, identify cultural differences, cross-cultural management to adopt a different strategy for cultural differences, so that the best two cultures combined, form their own core competitiveness.

Make the Cross-Cultural Training and Establish a High-Quality Cross-Cultural Team. In order to strengthen awareness of different cultural traditions of reaction and ability to adapt, to facilitate communication between people from different cultural backgrounds and understood that the implementation of cross-cultural training. Cross-cultural training main content of cultural awareness, cultural sensitivity training, language learning, intercultural communication and conflict handling area environment simulation, so that staff exposure to different cultural backgrounds working environment, develop their international perspective. This requires a number of high-quality cross-cultural management. Thus, managers of foreign parent sent not only to have good professionalism, knowledge and management ability, thought must also be flexible and do not abide by conventions, strong adaptability, respect, strong sense of equality, to tolerate different opinions, good with a variety of different cultural backgrounds and friendly cooperation. Where possible, try to choose those who understand Chinese culture and Chinese people has undergone training in a multicultural environment and understand. In the formation of the company's internal 
management team, but also to deal with the Chinese management personnel adequate cross-cultural management training Chinese managers to realize the business philosophy of understanding and recognition. Such a dual cultural identity has high-quality management team will effectively make early warning of possible conflicts or processing, conducive to the healthy development of enterprises.

Establish a Corporate Culture With Common Core Values. As an important part of corporate culture and values is a persistent belief that it can regulate employee behavior, communication guidelines. Foreign-funded enterprises, people should learn to respect and understand each other's culture, and equal manner, through mutual exchanges find the point of two cultures, the advantages of the two cultures, in-house and gradually establish a unified values. These values will become the most valuable asset, and it will become the cornerstone of the source of power enterprises to grow. Therefore, the core values of corporate culture is the highest goal of cross-cultural management, of course, is also the most difficult to accomplish goals. This requires all managers and employees of enterprises should on the basis of common understanding of the culture, according to the principles and requirements of the company's strategic development environment, constantly adjusting, constantly learning from the concept of co-operation beginning, and gradually establish a strong corporate culture. So that each employee can put their thoughts and behavior with business philosophy and purpose of the combine, while establishing a good reputation in the international market, and enhance the company's international business cultural change capability.

Establish Long-Term Development Goals and Realize Mutually Benefit. Foreign companies in China's cross-cultural management can not be achieved, it is a gradual process. From the formation of cross-cultural ideas, cultural integration until the establishment of unified values and it will require a longer time to adapt, not be so anxious. Therefore, enterprises in China must have long-term development goals. On the basis of the long-term development it should also achieve mutual benefit and common development of the Chinese and foreign parties to achieve a win-win situation. There is reason to believe that every violent conflict occurring in foreign-funded enterprises in China will not be the real winners appear, and through appropriate cross-cultural management, it is possible to achieve win-win situation. To avoid suicide, labor conflicts, failed investments and other tragic results, cross-cultural management is a lesson many companies must make up on. Specific management methods, implementation details such as way that people need to be more in-depth study.

\section{Acknowledgements}

Fund Project: 2016 Annual Henan Science and Technology Agency Soft Science and Technology Projects (162400410425).

\section{References}

[1] Jin Yibing. Economic and Cultural, Vol. 1 (2001) No 53, p.49-50

[2] Pat • Qiao Ente. Dongbei University of Finance and Economics, Vol. 12 (1999) No 27, p.74-76

[3] Han Lihong. Nankai University, Vol. 30 (2006) No 19, p.144-145

[4] Zhu Wenshan, Chen Jiqian. Industrial Technology \& Economy, Vol. 5 (1997) No 27, p.62-65

[5] Zhao Wenxia, Kong Haiyang. Economy Forum, Vol. 17 (2008) No 27, p.74-75

[6] Jiao Liang, Zhou Xianzhong. Management Innovation, Vol. 4 (2009) No 6, p. 107-108

[7] Dou Weilin. Foreign Economic and Trade University, Vol. 5 (2007) No 27, p.62-65 